МАТНЕМАТІСА, 60 (83), $\mathrm{N}^{\circ}$ 1, 2018, pp. 21-31

\title{
EXISTENCE OF SOLUTION FOR THIRD-ORDER THREE-POINT BOUNDARY VALUE PROBLEM
}

\author{
NOUREDDINE BOUTERAA and SLIMANE BENAICHA
}

\begin{abstract}
By imposing some conditions on the nonlinear term $f$, we construct a lower solution and an upper solution to prove the existence of a solution for a type of nonlinear third-order nonlocal boundary value problem. Our main tools are the upper and the lower solution method and the Schauder fixed point theorem. The results are illustrated by an example.
\end{abstract}

MSC 2010. 34B10, 34B15.

Key words. Positive solution, existence, lower and upper solutions.

\section{REFERENCES}

[1] D.R. Anderson, Existence of solution for some third-order boundary value problems, Electron. J. Differential Equations, 25 (2008), 1-6.

[2] N. Bouteraa and S. Benaicha, Triple positive solutions of higher-order nonlinear boundary value problem, Journal of Computer Science and Computational Mathematics, 7 (2017), 25-30.

[3] Z.B. Bai, Green's function for a third-order generalized right focal problem, J. Math. Anal. Appl., 288 (2003), 1-14.

[4] S. Clark and J. Henderson, Uniqueness implies existence and uniqueness criterion for a nonlocal boundary value problems for third-order differential equations, Proc. Amer. Math. Soc., 134 (2006), 3363-3372.

[5] K. Dimling, Multivalued differential equations, Walter De Gruyter, Berlin, 1982.

[6] Y. Feng and S. Liu, Solvability of a third-order two-point boundary value problem, Appl. Math. Lett., 18 (2005), 1034-1040.

[7] M. Gregus, Third order linear differential equations, D. Reidel Publishing Company, Dordrecht, 1987.

[8] C.P. Gupta, A generalized multi-point boundary value problem for second-order ordinary differential equations, Appl. Math. Comput., 89 (1998), 133-146.

[9] M.R. Grossinho and F.M. Minohs, Existence result for some third-order separated boundary value problems, Nonlinear Anal., 47 (2004), 2407-2418.

[10] L.J. Guo, J.P. Sun and Y.H. Zhao, Existence of positive solution for nonlinear thirdorder three-point boundary value problem, Nonlinear Anal., 68 (2008), 3151-3158.

[11] F. Haddouchi and S. Benaicha, Multiple positive solutions for a nonlinear three-point integral boundary value proble, International Journal of Open Problems in Computer Science and Mathematics, 8 (2015), 29-42.

[12] F. Haddouchi and S. Benaicha, Positive solutions of a nonlinear three-point eigenvalue problem with integral boundary value conditions, Rom. J. Math. Comput. Sci., 5 (2015), 202-213.

DOI: 10.24193/mathcluj.2018.1.03 
[13] R. Ma, A survey on nonlocal boundary value problems, Appl. Math. E-Notes, 7 (2007), $257-279$

[14] A. Rezaigia and S. Kelaiaia, Existence of positive solution for a third-order three-point boundary value problem, Mat. Vesnik, 68 (2016), 12-25.

[15] S. Reich and D. Shoikhet, Nonlinear semi group, fixed points and geometry of domains in Banach spaces, Imperial College Press, London, 2005.

[16] L. Shuhong, Positive solutions of nonlinear singular third-order two-point boundaryvalue problem, J. Math. Anal. Appl., 323 (2006), 413-425.

[17] J.P. Sun and H.E. Zhang, Existence of solutions to third-order m-point boundary value problems, Electron. J. Differential Equations, 125 (2008), 1-9.

[18] Y. Sun, Positive solutions for third-order three-point nonhomogeneous boundary value problems, Appl. Math. Lett., 22 (2009), 45-51.

[19] F.J. Torres, Positive solutions for a third-order three-point boundary-value problem., Electron. J. Differential Equations, 147 (2013), 1-11.

[20] Q. Yao, The existence and multiplicity of positive solutions for a third-order three-point regular boundary value problem, Acta Math. Appl. Sinica, 19 (2003), 117-122.

[21] Q. Yao, Positive solutions of a weak semipositone third-order three-point boundary value problem, Journal of Mathematical Research \& Exposition, 30 (2010), 173-180.

[22] L. Zhang, B. Sun and C. Xing, Existence of solutions to a third-order three-point boundary value problem, Annals of Differential Equations, 3 (2012), 368-372.

Received June 28, 2017

Accepted November 03, 2017
University of Oran 1, Ahmed Ben Bella

Laboratory of fundamental and applied mathematics

Es-senia, 31000 Oran, Algeria

E-mail: bouteraa-27@hotmail.fr

E-mail: slimanebenaicha@yahoo.fr 